\title{
Online sales system and organization outcome
}

\section{Nader Mohammad Aljawarneh ${ }^{a^{*}}$, Khalid talal alhindawi ${ }^{a}$, Ahmed Ghazi Mahafzah ${ }^{a}$, Shadi Mo- hammad Altahat ${ }^{\text {a }}$, Ebtehal Alzboun ${ }^{a}$ and Ibrahim Mohammad Harafsheh ${ }^{a}$}

\begin{tabular}{l}
${ }^{a}$ College of business, Jadara Universit \\
\hline C H R O N I C L E \\
\hline Article history: \\
Received: September 20, 2020 \\
Received in revised format: \\
January 15, 2021 \\
Accepted: January 16, 2021 \\
Available online: January 16, 2021 \\
\hline Keywords: \\
Online sales systems \\
Infrastructure \\
Ease of use \\
Information accuracy
\end{tabular}

\section{Introduction}

E-commerce allows conducting business transactions from sales, purchases, etc. in a more productive manner, therefore, offering greater opportunities and lower costs through the use of IT infrastructure, databases and electronic safety tools (Aljawarneh et al., 2020). This also helps to create good relations between the company and its customers and suppliers (Manzoor, 2010; Al-Jawarneh, 2016). E-commerce reflects transactions related to the selling and purchasing of goods or services over the Internet. Such transactions are carried out using electronic systems such as the Internet and other networks (Aljawarneh \& Al-Omari, 2018). These types of transactions that are done electronically have risen significantly, and the Internet has expanded with this expansion. A broad variety of business transactions has grown in this way, such as electronic money transfer, supply chain management, Internet marketing, online transaction processing, inventory management systems, and automated data collection systems (Mohapatra, 2013; Al-Jawarneh, 2016). With the growing use of the Internet, electronic forms of purchase of products are not only available in the field of e-commerce between the company and the consumer but also in the field of private purchasing between company and client (Mahafzah et al., 2020). Four advances are being made in the area of e-procurement: the sales side systems, the purchasing side systems, the exchange of products and the markets (Alomari et al., 2020). The sales side systems are the systems for the purchasing of certain products which the manufacturer places on the Internet The supplier manages this system; OSS defines the rules and explains how customers should use the system.A company that offers bids from suppliers develops the system for the side of the purchase. The company receives offers from several suppliers and can, therefore, select the best one (Kurbel, 2013; Aljawarneh \& Al-Omari, 2018). In most cases, it is much easier and cheaper to sell products and services over the Internet than traditional trading. The use of electronic commerce in electronic transactions now helps many small, medium and large companies (Alshare et al., 2020). Some companies use electronic means in $100 \%$ of their main activities (Gurevych, 2007; Al-Omari, 2020). Organizations have begun * Corresponding author.

E-mail address: n.jawarneh@jadara.edu.jo (N. M. Aljawarneh)

(C) 2021 by the authors; licensee Growing Science, Canada. doi: $10.5267 /$ j.ijdns.2021.3.004 
their activities or tasks in the relation to the permanent procedure regarding change ensuing out of friend instability yet into their environment, for that reason they are trying according to a spread of capacities or resources (Al-Omari et al., 2020). Even though they are well aware of the expected capacities yet assets are changing between their characteristics, and then reflected in the presentation regarding the business enterprise (Armbrust et al., 2010; Aljawarneh \& Atan, 2018).

The running provision targets are consistent with persuading clients to repeat the purchase of features via the uses regarding beneficial practices and methods after their enhancing yet maintaining consumer loyalty. The features of consumers are changing rapidly, competition among businesses is fierce, technological traits are growing, corporations are searching for globalization. As a result, the JRCCPE aims for nice structures because of managing procedures, workflow, controlling one of a kind processes, apportionment data and facts regarding one of a kind useful things to do then lowering inventory. Waste in accordance with achieving competitiveness, sustainability, minimize costs, efficaciously enlarge overall performance and effectively rule customer needs. Living up to expected modifications as the makeup of JRCCPE includes OSS. The instruction hassle stems out of the desire to identify the role and dimensions regarding the working system of the advertising related to optional protocol or its dimensions between JRCCPE. The discipline's issues were proved by addressing the following questions: what is the effect of OSS, infrastructure, ease of use \& information accuracy on JRCCPE? What is the level of applying OSS at JRCCPE? The subject of this study is respectable, as JRCCPE quantity is an authorization success factor of any given organization. It is also hoped that this study presents a cornerstone for other studies, given that directory about online income researchers along with results, help JRCCPE within online sales system improvement with the aid of running systems, demonstrating the fantastic function regarding the working regulation between JRCCPE supports.

\section{Literature Review}

\subsection{OSS, infrastructure, ease of use, information accuracy}

OSS is characterized as the activity in which software interaction aims to improve customer satisfaction through the business exchange for mutual benefit (Parvinen et al., 2014). The Internet offers the sale of goods, whether it is online or offline payments, as sales are made using the website of the company or third parties' websites (Basiouni and Alojairí, 2012).

Infrastructure is the basis of networks, devices, programs, processes, and resources that must be available prior to e-commerce applications created by the organization. The infrastructure can be internal or external to the company (Jennex, 2004). Jordan's telecommunications infrastructure is powerful and can support e-commerce via a stable telecommunications network. The private sector, however, must contribute to improving the public and private infrastructure of technology. Establishing such infrastructure will make many of these industries based on e-commerce and will provide important economic inputs to national income (Al-Shboul \& Alsmadi, 2010). As pointed out by Becker (2007), the core components of e-commerce infrastructure include infrastructure services, legal and regulatory framework, a set of open standards for technical services such as security, network protocols, e-mail and information exchange. It also includes infrastructure services for the Internet Business Link Network, directory of search and retrieval services, telecommunication security services, payment insurance services and ecommerce providers (Al-Da'abseh et al., 2018). Spotts \& Meadow, 2014 noted that ease of use is easy, convenient, and hasslefree purchasing from the corporate website, affecting customer satisfaction in their online shopping experience. Ease of use is the degree to which a client believes that the effort expended using a particular system will be minimal (Muller, 2012, 27). Therefore, once technology can be easily used, it will require less effort on the part of users, making it more likely to be implemented and used (Xu, 2013). The accuracy of the information illustrates the accuracy of stored information on the website, which accurately fits and matches the information (Nelson et al., 2005; Al-Omari, et al., 2018). It also can define the correctness of the data or the honesty of the data representation (Sebastian-Coleman, 2012, 64). Dealing with accurate data will be reflected positively on systems as they will become better and more capable to extract information from data, which increases the importance of data accuracy (Al-Omari et al., 2018). Along with complicated systems, data errors are more likely to develop, requiring the development of data recovery techniques (Kent \& Williams, 1993). There are several sources of data inaccuracy impacting data quality, which demonstrates the need for a comprehensive program of assessment, monitoring, and optimization. Errors occur in four general areas which are: initial data entry, data corruption, data transfer, and restructuring (Alzoubi et al., 2020). Database errors are caused by the first three factors, the inaccuracy of the output of information extracted from the data is resulted by the fourth factor (Banyhamdan et al., 2020). Moreover, the most important use of data is when it is represented for decision making in the company errors (Olson, 2003).

\subsection{JRCCPE}

Performance is a suitable concept regarding joining different layers about efficiency and effectiveness. While efficiency is the ratio of manufacturing in conformity with input, effectiveness is the dimension in imitation of as the organization's objective is achieved, as organizational strategies seek high-quality results. According to the theory of dictation in management science, overall performance is interpreted as "completed action instituted by means of an officer" (Wang, 1997). Organizational conduct, however, refers in accordance with performance namely "a built-in godsend component on affectivity and effectiveness" (Hsieh, 2006; Al-Jawarneh, 2016). The benefits regarding organizational overall performance pleasure ultimately reply according to the monetary dimension. Regarding that, most researchers rely upon pecuniary performance as an indicator related to measurement among surroundings without problems dispatched statistics and rapidly altering markets, but nowadays the employer is not only depending on monetary overall performance for progress after competitiveness (Alwagfi et al., 2020). Based on countless indicators that help them of the procedure regarding measuring ADA, it is not possible to abandon 
organizational performance entirely using economic performance as the sole metering regarding performance (Ling and Hung, 2010; Aljawarneh et al., 2020). Consequently, organizational performance reflects achievements by using the employer and the departments concerned among an organizational objective over a particular length over time, the place the goal is either a particular segment yet a total scope. Based on many studies, astronaut funding impacts organizational performance (Ling or Hung, 2010). Where empirical performance is decent through innovation performance, which is measured beyond more than one view over organizational innovation (Alsafadi et al., 2020). like empiric then managerial innovations. Even though empirical innovations refer to the required technologies via the agency in conformity with manufacture merchandise, it also provides services, as administrative innovation takes place within the conventional rule related to the organization after it is attached after recruitment, management and organizational structure (Huang, 2014). Thus, the following hypotheses were proposed:

Hypothesis 1: There is no relationship between online sales system infrastructure and JRCCPE. Hypothesis 2: There is no relationship between online sales system ease of use and JRCCPE.

Hypothesis 3: There is no relationship between online sales system information accuracy and JRCCPE.

Hypothesis 4: There is a significant difference to OSS for sample study evaluation level depending on demographic variables.

\section{Research Method}

This study explores the methods or techniques used to conduct research on the role of the working system among JRCC operations. The researcher described techniques and sequences for which information was collected for analysis or hypothesis testing. Due to this lookup instruction, data was collected by using the most important data source. A quantitative approach was used in this research to identify the role of OSS in improving JRCCPE. In addition, primary data was collected from questionnaires. Consequently, after collecting and analyzing the data, the results were discussed; and the conclusion and recommendations were reached. Regarding study population, it consisted of all employees from JRCC in Jordan, where the sample was 220 employees from the set of employees working in OSS. The analysis unit included all JRCC employees from the set of employees working in OSS.

\subsection{Content validity}

The veracity of each variable's paragraphs of the study is different from the variable to which it belongs. Each variable is accurately represented by a set of paragraphs (Sekaran \& Bougie, 2014). Regarding the validity of the questionnaire, Spearman Coefficient Correlation (SCC) was used to measure the relationship between each paragraph and its variable. Alshwiyat, 2013 indicated that the paragraphs with a correlation greater than $30 \%$ are statistically significant and acceptable to measure the variable to which the paragraphs belong. Table 1 shows that all coefficients regarding the link between the paragraphs and the variable to which they belong were greater than $30 \%$, which proves a structural validity of these paragraphs in relation to their own variables. In order to measure the validity of the content of the questionnaire variables, SCC was used to measure the relationship between each variable and the total score of the resolution paragraphs. The correlations that are greater than $30 \%$ were adopted and significant.

Table 1

SCC for the Content validity

\begin{tabular}{|c|c|c|c|c|c|c|c|c|}
\hline \multirow{2}{*}{ Items } & \multicolumn{2}{|c|}{ Infrastructure } & \multicolumn{2}{|c|}{ Ease of use } & \multicolumn{2}{|c|}{ Information accuracy } & \multicolumn{2}{|c|}{ JRCCPE } \\
\hline & Correlation & Sig. & Correlation & Sig. & Correlation & Sig. & Correlation & Sig. \\
\hline 1 & 0.602 & 0.000 & 0.721 & 0.000 & 0.698 & 0.000 & 0.578 & 0.000 \\
\hline 2 & 0.695 & 0.000 & 0.821 & 0.000 & 0.704 & 0.000 & 0.693 & 0.000 \\
\hline 3 & 0.704 & 0.000 & 0.609 & 0.000 & 0.815 & 0.000 & 0.721 & 0.000 \\
\hline 4 & 0.621 & 0.000 & 0.725 & 0.000 & 0.598 & 0.000 & 0.675 & 0.000 \\
\hline 5 & 0.589 & 0.000 & 0.750 & 0.000 & 0.649 & 0.000 & 0.625 & 0.000 \\
\hline 7 & & & & & & & 0.635 & 0.000 \\
\hline 8 & & & & & & & 0.748 & 0.000 \\
\hline 9 & & & & & & & 0.831 & 0.000 \\
\hline 10 & & & & & & & 0.791 & 0.000 \\
\hline 11 & & & & & & & 0.698 & 0.000 \\
\hline \multirow[t]{3}{*}{12} & & & & & & & 0.726 & 0.000 \\
\hline & \multicolumn{2}{|c|}{ With instrument } & \multicolumn{2}{|c|}{ With instrument } & \multicolumn{2}{|c|}{ With instrument } & \multicolumn{2}{|c|}{ With instrument } \\
\hline & $\cdot, \wedge \leq Y$ &,$\ldots$ & $\cdot, \vee \vee 91$ & $\cdot, \ldots$ & $\cdot, \vee \vee \wedge \uparrow$ & $\cdot, \ldots$ & $\cdot, \wedge Y 1$ & $\cdot, \ldots$ \\
\hline
\end{tabular}

\subsection{Reliability \& Normal Distribution Test}

The tool is consistent with the possibility of obtaining the same data when reproducing the study using the same study tool on the same individuals under similar conditions. The tool was used entirely to measure the stability of each variable. The Cronbach Alpha is a statistically acceptable value 70\% (Sekaran \& Bougie, 2014, p268). In the analysis of the data, the results indicated in Table 2 that there is high stability for all the variables of the study. As for the normal distribution of the data, the results of the One-Sample Kolmogorov-Smirnov Test in Table 2 indicated that all the $Z$ values of the study variables were statistically insignificant, indicating that the data of the study variables follow a normal distribution. 
Table 2

Reliability \& Normal Distribution Test

\begin{tabular}{|c|c|c|c|c|c|}
\hline Part & Variable & No. of items & Cronbach Alpha & K-S ( Z) & Sig. \\
\hline \multirow{4}{*}{ OSS } & Infrastructure & 5 & $0 . \wedge 77$ & $1,10 r$ & $0.1 T Y$ \\
\hline & Ease of use & 0 & $0 . \vee \leq 0$ & 1, & $\cdot, 990$ \\
\hline & Information accuracy & $\circ$ & $0 . \wedge 9 \leq$ & 1, YTO & $0 . \cdot \vee \varepsilon$ \\
\hline & Total OSS & 15 & 0.912 & $\cdot, \times 01$ & $\cdot,\{91$ \\
\hline \multirow[t]{2}{*}{ JRCCPE } & & Ir & 0.853 & 1.119 & $0.1 Y$. \\
\hline & Total & $r V$ & 0.956 & $0.70 \leq$ & $\cdot, \leqslant 11$ \\
\hline
\end{tabular}

\subsection{Study sample characteristics}

As shown in Table 3, male respondents are 84, representing $55.26 \%$ of the sample, while female respondents are 68 , which is $44.74 \%$ of the sample. As expected, the number of male respondents was slightly higher. Regarding academic achievement, most respondents held a bachelor's degree representing a percentage of 55.92\%. Master's degree holders represented the second largest category, with a percentage of $31.58 \%$, whereas doctorate's degree holders came in third place, representing $12.50 \%$ of the sample. Regarding the final personal variable, age of participants, most participants were 20-30 years old representing $31.58 \%$ of the sample, whereas $27.63 \%$ of the sample was those under 20 years old, and lastly placed those who were 51 years old or older representing $7.89 \%$ of the sample.

Table 3

The distribution of study sample depends on personal variables $\mathrm{n}=1$ or

\begin{tabular}{|c|c|c|c|}
\hline personal variables & Frequency & Percentage & Cumulative Percent \\
\hline \multicolumn{4}{|l|}{ Gender } \\
\hline Male & 84 & 55.26 & 55.26 \\
\hline Female & 68 & 44.74 & 100.00 \\
\hline \multicolumn{4}{|l|}{ Qualification } \\
\hline Bachelor & 85 & 55.92 & 55.92 \\
\hline Master & 48 & 31.58 & 87.50 \\
\hline Doctorate & 19 & 12.50 & 100.00 \\
\hline \multicolumn{4}{|l|}{ Age } \\
\hline less than 20 year & 42 & 27.63 & 27.63 \\
\hline 20-30 year & 48 & 31.58 & 59.21 \\
\hline $31-40$ year & 33 & 21.71 & 80.92 \\
\hline $41-50$ year & 17 & 11.18 & 92.11 \\
\hline 51 year or more & 12 & 7.89 & 100.00 \\
\hline
\end{tabular}

\section{Data Analysis and Results}

\subsection{First: OSS}

Infrastructure: Table 4 illustrates the means and standard deviations of the infrastructure variable from the perspective of the participants of the study sample, which is employees who used the OSS of the JRCCPE based on their importance, and it was determined through their means.

Table 4

The Attitudes of the participants concerning infrastructure

\begin{tabular}{|c|c|c|c|c|c|c|}
\hline Order & No. & Items & Mean & SD & Skewness & Degree \\
\hline 1 & 4 & JRCC provides several ways to facilitate as a bill payment process. &.$\leqslant 21$ & 0.72 & 0.62 & High \\
\hline 2 & 1 & JRCC maintains hardware and software for online sale. & . 18 & 0.81 & -0.67 & High \\
\hline 3 & 3 & JRCC provides hardware and software to complete online sale. &.$£ 15$ & 0.72 & -0.92 & High \\
\hline 4 & 2 & The JRCC database is constantly updated. &.$\leqslant 02$ & 0.89 & -0.79 & High \\
\hline 5 & 5 & JRCC use modern means of communication. & 3.98 & 1.02 & 0.62 & High \\
\hline & & General tendency (Infrastructure) & 4.11 & 0.69 & -0.71 & High \\
\hline
\end{tabular}

The arithmetic mean of the responses of the sample members who are users of the OSS regarding infrastructure were significant for all the paragraphs, ranging from 3.98 to 4.21, as shown in Table 4. The SD of the responses did not reflect a high degree of dispersion, ranging from 0.72 to 1.02 which indicates a consensus in the answers supporting the provision of infrastructure in the restaurants. When reviewing the ranking of the paragraphs, it was found that paragraph 4, which states "JRCC provides several ways to facilitate as a bill payment process", represented the greatest significance, and had a Mean $=4.21$, $\mathrm{SD}=0.7$. Secondly, paragraph 1, which states that "JRCC stores hardware and software for online sale", had a mean $=4.18$, $\mathrm{SD}=0.81$ and was within the high level of significance. While paragraph 5 placed lastly, stating that "JRCC uses modern means of communication ", with a mean $=3.98, \mathrm{SD}=1.01$ and within the level of high significance. The overall results indicate a high level of infrastructure availability at JRCC, with an average of 4.11, indicating the management's understanding of providing the infrastructure necessary for the success of OSS. 
Ease of use: Table 5 illustrates the means and standard deviations of the ease of use variable from the perspective of the participants of the study sample, which is employees who used the online sales of the BCR based on their importance, and it was determined through their means.

Table 5

The Attitudes of the participants concerning ease of use

\begin{tabular}{|c|c|c|c|c|c|c|}
\hline Order & No. & Items & Mean & SD & Skewness & Degree \\
\hline 1 & 8 & $\begin{array}{l}\text { The JRCC online sale applications allow easy navigation between sys- } \\
\text { tem orders. }\end{array}$ &.$\leqslant 31$ & 0.65 & -0.56 & High \\
\hline 2 & 6 & $\begin{array}{l}\text { The JRCC online selling system provides tools for help and explana- } \\
\text { tion. }\end{array}$ &.$\leqslant 19$ & 0.64 & -0.94 & High \\
\hline 3 & 9 & JRCC online sale software allows user interface control. & $\varepsilon 17$ & 0.53 & 0.65 & High \\
\hline 4 & 7 & The JRCC online sale system is easy to enter data. & $\therefore 09$ & 0.78 & -0.64 & High \\
\hline 5 & 10 & The online sale system of JRCC is easy to find in its contents. & $\varepsilon 01$ & 0.81 & -0.69 & High \\
\hline & & General tendency (ease of use) & 4.15 & 0.48 & -0.57 & High \\
\hline
\end{tabular}

The arithmetic mean of the responses of the study sample members regarding ease of use was very significant for all paragraphs, as shown in table 5. The arithmetic means ranged between $4.01-4.31$ and the standard deviation of the responses did not reflect a high degree of dispersion, ranging from 0.53 to 0.81 which shows consensus in the answers that support the ease of use. Reviewing the order of the paragraphs, it was found that paragraph 8, which stated that "The JRCC online sale applications allow easy navigation between system orders", was the most significant, with a mean $=4.31, \mathrm{SD}=0.65$, and falls within the high level of significance. Paragraph 6 placed secondly, and which states that "the JRCC online selling system provides tools for help and explanation", with a mean $=4.19, \mathrm{SD}=0.64$, and is within the high level of significance. Meanwhile, paragraph 6 placed lastly, and which states "The online sale system of JRCC is easy to find in its contents "and mean $=4.01, \mathrm{SD}=0.81$, and is within the level of high significance. Overall, the results indicate that the BCR system is easy to use by customers with an average of 4.15 . This shows that the restaurant management has consistently sought to make the system easy to use by all target groups for the success of OSS.

Information accuracy: Table 6 illustrates the means and standard deviations of the information accuracy variable from the perspective of the participants of the study sample, which is employees who used the OSS of the JRCC based on their importance, and it was determined through their means.

\section{Table 6}

The Attitudes of the participants concerning information accuracy

\begin{tabular}{|c|c|c|c|c|c|c|}
\hline Order & No. & Items & Mean & SD & Skewness & Degree \\
\hline 1 & 11 & $\begin{array}{l}\text { JRCC online sale system is characterized by the integration of infor- } \\
\text { mation. }\end{array}$ &.$\leqslant 32$ & . & -0.82 & High \\
\hline 2 & 14 & JRCC online sale information is accurate. & .224 & $\cdot, \mathrm{VT}$ & 0.49 & High \\
\hline 3 & 13 & The online sale system occurs continuously in the database. & $\therefore 16$ & $\cdot, \mathrm{V} 7$ & -0.69 & High \\
\hline 4 & 15 & $\begin{array}{l}\text { The JRCC online sale system provides information to help managers } \\
\text { make decisions. }\end{array}$ &.$\leqslant 07$ & $\cdot, v_{0}$ & -0.79 & High \\
\hline 5 & 12 & $\begin{array}{l}\text { The JRCC online sale system is comprehensive in presenting infor- } \\
\text { mation. }\end{array}$ &.$\leqslant 02$ & $\cdot, V \varepsilon$ & -0.83 & High \\
\hline & & General Tendency (information accuracy) & 4.16 & 0.53 & -0.61 & High \\
\hline
\end{tabular}

The arithmetic means of the responses of the sample members regarding accuracy of the information were very high for all the paragraphs, which can be seen in table 6. The arithmetic means ranged between $4.02-4.32$ and the SD of the responses did not reflect a high degree of dispersion, ranging from 0.62 to 0.76 , which shows a consensus in the answers that support the accuracy of the system information. Reviewing the order of paragraphs, it was found that paragraph 11, which states that "JRCC online sale system is characterized by the integration of information", was of the greatest significance, with a mean = $4.32, \mathrm{SD}=0.62$, and is within the high level of significance. Paragraph 14 was secondly placed, and which stated that "JRCC online sale information is accurate", with a mean $=4.24, \mathrm{SD}=0.76$, and is within the high level of significance. Meanwhile, paragraph number 12 was placed lastly, and which states that "The JRCC online sale system is comprehensive in presenting information", with a mean $=4.02, \mathrm{SD}=0.74$, which is within the high level of significance. Overall, the results indicate that the JRCC system provides accurate information about the service provided at an average of 4.16. This shows that the restaurant management work towards providing accurate information to customers about the services available for the success of the online sales process.

\subsection{Second: JRCCPE}

Table 7 illustrates the means and standard deviations of the organizational performance variable from the perspective of the participants of the study sample, which is employees who use the online sales of the BCR based on their importance which is determined through their means. 
Table 7

The Attitudes concerning JRCCPE

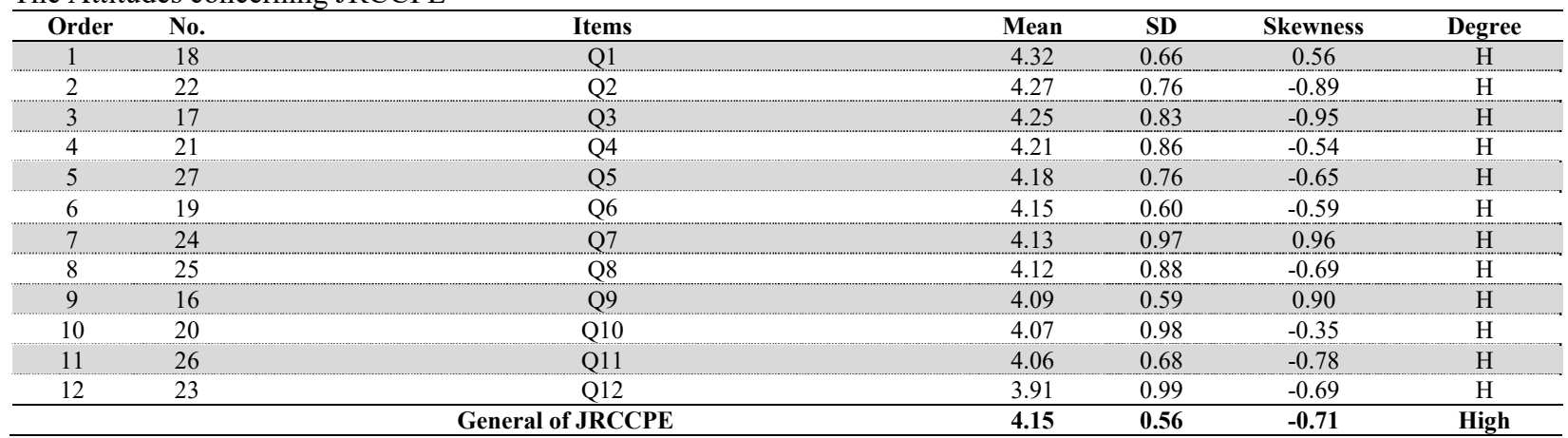

Table 7 demonstrates that the arithmetic means ranged 3.91 between 4.32 and the standard deviation of the responses did not reflect a high degree of dispersion. Consensus appears in the responses that support the conviction of JRCCPE. By reviewing the order of the paragraphs, it was found that paragraph 18, which states that "the management of the company to demonstrate operations continuously", was of the greatest significance, with a mean $=4.32, \mathrm{SD}=0.66$, and was within a level of high significance. In second place came paragraph 22 with a mean $=4.27, \mathrm{SD}=0.76$, which is within the high level of significance. Lastly, paragraph 23 came, and which states "Directors are keen to improve learning efficiency for different operations ", with a mean $=3.91, \mathrm{SD}=0.99$, and is also within the level of high significance. Overall, the results indicate that the level of JRCCPE is high and averaged 4.15. This shows the realization of the sample of the study that the management is working to improve the JRCCPE to provide the as best service as possible.

\subsection{Hypotheses Testing}

The researcher examined the regression model in accordance to confirm that it is not high outset in unbiased variables or Brooks, 2008 where correlation is more than $80 \%$ between a couple of impartial variables. Table eight demonstrates that there is no excessive correlation within study independent variables, so lots of them can have an effect on the outcomes over regression analysis.

\section{Table 8}

$\underline{\mathrm{SCM}}$

\begin{tabular}{|c|c|c|c|c|}
\hline Variable & Infrastructure & Ease Of Use & Information Accuracy & JRCCPE \\
\hline Infrastructure & 1.000 & & & \\
\hline Ease Of Use & $.549 * *$ & 1.000 & & \\
\hline Information Accuracy & $.462 * *$ & $.521 * *$ & 1.000 & \\
\hline JRCCPE & $.768 * *$ & $.697 * *$ & $.631 * *$ & 1.000 \\
\hline
\end{tabular}

**Correlation is significant at the 0.01 level (2-tailed).

Multiple linear regression (MLR)was used to identify the effect of OSS on JRCCPE in PCR. As shown in table 9, there is a significant effect of OSS use on JRCCPE, with a correlation coefficient of 0.744 which is a statistically significant value, indicating a strong positive correlation between OSS use and JRCCPE and an adjusted R of 0.586 which is able to interpret $58.6 \%$ of the variance of JRCCPE, which is confirmed by the value of F-value of 46.333, and that is below the level of significance, indicating the existence of a relationship between the independent variables and dependent variable. Based on the above, the null hypothesis is rejected and the alternative hypothesis is accepted.

Table 9

MLR for effect of the OSS on JRCCPE

\begin{tabular}{|c|c|c|c|c|c|c|}
\hline Variables & Expected sign & Coefficient & t-Statistic & Prob & Tolerance & *VIF \\
\hline (Constant) & & 0.564 & 1.823 & .045 & & \\
\hline Infrastructure & +1 & 0.194 & 2.064 & 0.042 & .585 & 2.061 \\
\hline Ease of use & +1 & 0.322 & 4.625 & .000 & .416 &.$r 402$ \\
\hline Information accuracy & $+/-$ & 0.223 & 2.138 & .035 & .501 & 1.997 \\
\hline $\mathrm{R}$ & 0.744 & \multicolumn{3}{|c|}{ F-statistic } & \multicolumn{2}{|c|}{46.333} \\
\hline R-squared & 0.599 & \multicolumn{3}{|c|}{ Prob (F-statistic) } & \multicolumn{2}{|c|}{0.000} \\
\hline Adjusted R Square & 0.586 & \multicolumn{3}{|c|}{ Durbin-Watson statistic } & \multicolumn{2}{|c|}{2.038} \\
\hline
\end{tabular}

All VIF values are less than 10 and indicate no self-association problem 
The results of regression coefficients show that $\beta$ values for all variables at different $\mathrm{T}$ levels are at the significance level, all of which are less than 0.05 . This confirms the significance of the regression coefficients and indicates that the effect of the variables is significant. For testing hypotheses separately, the simple linear regression (SLR) analysis was used. Table 10 shows the results related to the first hypothesis.

Table 10

Results of SLR test of infrastructure on OP

Independent Variable $\quad 0.62$
Infrastructure

\begin{tabular}{cccccc}
$\mathbf{R}$ & $\mathbf{R}^{\mathbf{2}}$ & F-value & Coefficient & T-value & Sig. \\
0.622 & 0.405 & 66.258 & 0.622 & 8.140 & 0.000 \\
\hline
\end{tabular}

As can be seen in Table 10, there is a positive correlation between infrastructure and OP with an $\mathrm{R}$ value of 0.622 . The $\mathrm{R}^{2}$ factor of 0.405 explains the variance in the dependent variable; that is $40.5 \%$ of the changes in OP resulted from the change in infrastructure which indicates the importance of this variable in improving OP. The table also shows a positive impact of the infrastructure on OP and an impact level of Coefficient $=0.622, \mathrm{p}>0.000$. This explains that a single increase in infrastructure leads to an improvement of OP by $62.2 \% \mathrm{~m}$ confirming that the value of $\mathrm{T} 8.140$ is statistically significant. Table 11 shows the results related to the test of $\mathrm{H}_{2}$.

Table 11

Results of SLR test of ease of use on JRCCPE

\begin{tabular}{ccccccc}
\hline Independent Variable & $\mathbf{R}$ & $\mathbf{R}^{\mathbf{2}}$ & F-value & Coefficient & T-value & Sig. \\
\hline ease of use & 0.726 & 0.543 & 114.874 & 0.726 & 10.718 & 0.000 \\
\hline
\end{tabular}

Table 11 demonstrates a positive correlation betweenease of use and JRCCPE with an $\mathrm{R}$ value of 0.726 . The $\mathrm{R}^{2}$ factor of 0.543 explains the variance in the dependent variable; that is $54.3 \%$ of the changes in JRCCPE resulted from the change in ease of usewhich indicates the importance of this variable in improving JRCCPE. The table also shows a positive effect of the ease of use on JRCCPE and an impact level of Coefficient $=0.726, p>0.000$. This explains that a single increase in ease of use leads to an improvement of JRCCPE by $72.6 \%$. This confirms that the value of T 10.718 is statistically significant. Table 12 shows the results related to the test of $\mathrm{H}_{3}$.

Table 12

Results of SLR test of information accuracy on JRCCPE

\begin{tabular}{lcccccc} 
Independent Variable & $\mathbf{R}$ & $\mathbf{R}^{\mathbf{2}}$ & F-value & Coefficient & T-value & Sig. \\
Information accuracy & 0.621 & 0.399 & 64.770 & 0.621 & 8.048 & 0.000 \\
\hline
\end{tabular}

Based on Table 12, there is a positive correlation betweeninformation accuracyandJRCCPEwith an $R$ value of 0.621 . The $R^{2}$ factor of 0.399 explains the variance in the dependent variable; that is $39.9 \%$ of the changes in JRCCPE resulted from the change in information accuracywhich indicates the importance of this variable in improving JRCCPE. The table also shows a positive impact of the information accuracy on JRCCPE and an impact level of Coefficient $=0.621, p>0.000$. This explains that a single increase in information accuracy leads to an improvement of JRCCPE by $62.1 \%$, conforming that the value of T 8.048 is statistically significant.

H4 test

1. Gender: As clear in Table 13, there is an unbiased pattern testing according to discover out the distinction in the assessment about operating system samples primarily based on gender variable.

Table 13

IST of OSS depending on Gender

\begin{tabular}{|c|c|c|c|c|c|c|}
\hline \multirow{2}{*}{ Variable } & \multicolumn{2}{|c|}{$\underline{\mathbf{M}}$} & \multicolumn{2}{|c|}{$\underline{\mathbf{F}}$} & \multirow{2}{*}{$\mathbf{T}$} & \multirow{2}{*}{ Sig. } \\
\hline & $\mathbf{M}$ & S.D & Mean & S.D & & \\
\hline Infrastructure & 4.142 & 0.762 & 4.074 & 0.625 & -0.092 & 0.923 \\
\hline Ease of use & 4.125 & .453 & 4.184 & 0.524 & 1.121 & 0.291 \\
\hline Information accuracy & 4.134 & 0.592 & 4.191 & 0.436 & 1.451 & 0.132 \\
\hline OSS & 4.134 & 0.429 & 4.149 & 0.394 & 1.121 & 0.295 \\
\hline
\end{tabular}

There is no effect, and the T-values were not significant.

2. Qualification: Table 14 shows the one-way ANOVA of OSS depending on qualification. 
Table 14

ANOVA of OSS

\begin{tabular}{|c|c|c|c|c|c|c|}
\hline $\mathbf{V}$ & Source & S of Squs & Df & Mean Squ & $\mathbf{F}$ & $P$ \\
\hline \multirow{3}{*}{ Infrastructure } & Between Groups & 3.357 & 2 & 1.679 & 2.349 & 0.076 \\
\hline & Within Groups & 44.801 & 249 & 0.179 & & \\
\hline & Total & 48.158 & 151 & & & \\
\hline \multirow{3}{*}{ Ease of use } & Between Groups & 2.138 & 2 & 1.069 & 1.484 & 0.224 \\
\hline & Within Groups & 47.073 & 249 & 0.189 & & \\
\hline & Total & 49.211 & 151 & & & \\
\hline \multirow{3}{*}{ Information accuracy } & Between Groups & 2.413 & 2 & 1.207 & 2.899 & 0.041 \\
\hline & Within Groups & 31.540 & 249 & 0.127 & & \\
\hline & Total & 33.953 & 151 & & & \\
\hline \multirow{3}{*}{ OS } & Between Groups & 2.237 & 2 & 1.119 & 2.228 & 0.090 \\
\hline & Within Groups & 32.795 & 249 & 0.132 & & \\
\hline & Total & 35.031 & 151 & & & \\
\hline
\end{tabular}

Moreover, Scheffe test was applied to find out the differences.

Table 15

Scheffe test for information accuracy depending on qualification

\begin{tabular}{lcccc}
\hline \multirow{2}{*}{ Qualification } & \multirow{2}{*}{ Mean } & Bachelor & Master & Doctorate \\
\cline { 3 - 5 } & & $\mathbf{4 . 0 5 2}$ & $\mathbf{4 . 1 4 4}$ & $\mathbf{4 . 2 8 3}$ \\
\hline Bachelor & 4.052 & & -0.092 & $\mathbf{0 . 2 3 1 * *}$ \\
Master & 4.144 & -0.092 & & 0.139 \\
Doctorate & 4.283 & $\mathbf{- 0 . 2 3 1 ^ { * * }}$ & -0.139 & \\
\hline
\end{tabular}

Table 15 illustrates differences in the answers of the study sample related to the accuracy of the information according to the qualification variable. The results indicated that the sources of the differences were between the bachelor and $\mathrm{PhD}$ degrees' categories, which were in favor of the $\mathrm{PhD}$ category with an average of 4.283 .

3. Age: Table 16 shows ANOVA for age variable.

Table 16

ANOVA for age

\begin{tabular}{|c|c|c|c|c|c|c|}
\hline $\mathbf{V}$ & Source & Sum of Squ & Df & Mean Squ & $\mathbf{F}$ & $\mathbf{P}$. \\
\hline \multirow{3}{*}{ Infrastructure } & Between Groups & 2.363 & 4 & 0.591 & 1.685 & 0.175 \\
\hline & Within Groups & 45.796 & 247 & 0.185 & & \\
\hline & Total & 48.158 & 151 & & & \\
\hline \multirow{3}{*}{ Ease of use } & Between Groups & 3.756 & 4 & 0.939 & 3.014 & 0.012 \\
\hline & Within Groups & 45.455 & 247 & 0.184 & & \\
\hline & Total & 49.211 & 151 & & & \\
\hline \multirow{3}{*}{ Information accuracy } & Between Groups & 0.878 & 4 & 0.219 & 0.867 & 0.461 \\
\hline & Within Groups & 33.076 & 247 & 0.134 & & \\
\hline & Total & 33.953 & 151 & & & \\
\hline \multirow{3}{*}{ Online Sales } & Between Groups & 1.400 & 4 & 0.350 & 1.360 & 0.259 \\
\hline & Within Groups & 33.631 & 247 & 0.136 & & \\
\hline & Total & 35.031 & 151 & & & \\
\hline
\end{tabular}

There is an effect in respondents about OSS (ease of use) depending on age, where (F) value was affected. Therefore, Scheffe test was applied to find out the differences.

Table 17

Scheffe test for variances of Ease of use depending on age

\begin{tabular}{|c|c|c|c|c|c|c|}
\hline \multirow{2}{*}{ Age } & \multirow{2}{*}{ Mean } & $<20$ year & $20-30$ year & $31-40$ year & $41-50$ year & $>=51$ year \\
\hline & & 4.242 & 4.143 & 4.152 & 4.171 & 4.065 \\
\hline less than 20 year & 4.242 & & -0.099 & -0.090 & -0.071 & $-0.177 * *$ \\
\hline 20-30 year & 4.143 & 0.099 & & 0.009 & 0.028 & -0.078 \\
\hline $31-40$ year & 4.152 & 0.090 & -0.009 & & 0.019 & -0.087 \\
\hline $41-50$ year & 4.171 & 0.071 & -0.028 & -0.019 & & -0.106 \\
\hline 51 year or more & 4.065 & $0.171 * *$ & 0.078 & 0.087 & 0.106 & \\
\hline
\end{tabular}

$* *$ The mean difference is significant levels at $5 \%$. 
The sources of the differences were between the age group less than 20 years and 51 years and above, which were in favor of the age group that is less than 20 years, with an average of 4.242, whereas the arithmetic mean of the age group 51 years and above which reached 4.065 .

\section{Findings \& Recommendations}

The study was driven by the need to help service managers such as JRCCPE to understand the role of OSS, infrastructure, ease of use \& information accuracy in JRCCPE. The study reached a number of results: The OSS has an impact on achieving the effectiveness of JRCCPE. There is an effect of infrastructure on achieving the effectiveness of JRCCPE. It also concluded that there is an effect of ease of use on achieving the effectiveness of JRCCPE, and information accuracy also has an impact on achieving the effectiveness of JRCCPE. Based on these results, the following is recommended in regards to JRCCPE: promote the concept of learning and knowledge sharing, to add features (editing, deleting, copying and time-setting) to text messaging across social networks, increase attention to customer satisfaction through studies or feedback, and conduct marketing studies aiming at enabling companies to achieve customer desires matching their expectations.

\section{References}

Al-Da'abseh, T. A. R. I. Q., Aljawarneh, N., \& Shwiyat, Z. (2018). Marketing mix startegies and its impact on organizational performance efficiency in the Jordanian company for investment and supply-safeway: An empirical study. Invention Journal of Research Technology in Engineering \& Management, 2(2), 14-23.

Al-Jawarneh, N. M. S. (2016). Case study: Business management school at the Turkish republic of north Cyprus and how strategic thinking and planning can improve the performance of the organization to maintain stable between competitors. Invention Journal of Research Technology in Engineering \& Management (IJRTEM), 1(5), 64-72.

Aljawarneh, N. M. S., \& Atan, T. (2018). Linking Tolerance to Workplace Incivility, Service Innovative, Knowledge Hiding, and Job Search Behavior: The Mediating Role of Employee Cynicism. Negotiation and Conflict Management Research, 11(4), 298-320.

Aljawarneh, N. M., Abd kader Alomari, K., Alomari, Z. S., \& Taha, O. (2020). Cyber incivility and knowledge hoarding: Does interactional justice matter?. VINE Journal of Information and Knowledge Management Systems.

Aljawarneh, N. M., Sokiyna, M., Obeidat, A. M., Alomari, K. A. K., Alradaideh, A. T., \& Alomari, Z. S. (2020). The Role of CRM Fog Computing on Innovation and Customer Service Quality: an Empirical Study. Marketing and Management of Innovations, 2, 286-297.

Aljawarneh, N., \& Al-Omari, Z. (2018). The Role of Enterprise Resource Planning Systems ERP in Improving Customer Relationship Management CRM: An Empirical Study of Safeway Company of Jordan. International Journal of Business and Management, 13(8), 86-100.

Alomari, K. A. K., Aljawarneh, N. M., Alomari, Z. S., Albdareen, R., \& Alawneh, A. (2020). Innovations in Knowledge Management Perspectives: An Empirical Study in the Jordanian Commercial and Islamic Banks. Marketing and Management of Innovations, 4, 102-119

Al-Omari, Z. S., Aljawarneh, N., Davut, S., \& Salah, A. (2018). The Impact of Marketing Mix Elements on Forming Mental Images about Islamic Banks in Jordan: An Empirical Study. OFFICIAL, 12, 54.

Al-Omari, Z., Alomari, K., \& Aljawarneh, N. (2020). The role of empowerment in improving internal process, customer satisfaction, learning and growth. Management Science Letters, 10(4), 841-848.

Alsafadi, Y., Aljawarneh, N., Çağlar, D., Bayram, P., \& Zoubi, K. (2020). The mediating impact of entrepreneurs among administrative entrepreneurship, imitative entrepreneurship and acquisitive entrepreneurship on creativity. Management Science Letters, 10(15), 3571-3576.

Alshare, F., Aljawarneh, N., Alomari, K., Alomari, Z., Albdareen, R., AAlwagfi, A., \& Alradaideh, A. (2020). Factors influencing cellular device purchase decisions in Jordan. Management Science Letters, 10(11), 2501-2506.

Al-Shboul, M., \& Al-Smadi, I. (2010). Building an e-Commerce Infrastructure in Jordan: Challenges and Requirements International, Journal of Interactive Mobile Technologies, 4(4), 18-24.

AL-Shwiyat, Z. M. M. (2013). The impact of Social Responsibility on the Financial Performance for Jordanian Companies, European Journal of Business and Management, 5(30), 123- 132.

Alwagfi, A. A., Aljawarneh, N. M., \& Alomari, K. A (2020). Work Ethics and Social Responsibility: Actual and Aspiration. Journal of Management Research, 12(1), 26-36.

Alzoubi, K., Aljawarneh, N. M., Alsafadi, Y., Al-Radaideh, A. T., \& Altahat, S. (2020). Role of Cloud Computing in Service Quality, Information Quality \& Low Costs: An Empirical Study on Jordanian Customs. International Journal of Academic Research in Business and Social Sciences, 10(6), 522-532.

Armbrust, M., Fox, A., Griffith, R., Joseph, A. D., Katz, R., Konwinski, A., ... \&Zaharia, M. (2010). A view of cloud computing. Communications of the ACM, 53(4), 50-58.

Banyhamdan, K. M. T., Aljawarneh, N. M., Alomari, M. A., Almasarweh, M. S., Harafsheh, I. M., \& Alwagfi, A. A. Impact of Human Capital in Quality and Strategic Excellences. International Journal of Advanced Science and Technology, 29 (7), 11702-11710.

Basiouni, A., \&Alojairi, A. (2012, June). Factors influencing firms to sell online in e-business challenging environment In Technology Management Conference (ITMC), 2012 IEEE International (pp. 332-338).IEEE. 
Becker, A. (2007). Electronic Commerce: Concepts, Methodologies, Tools, and Applications: Concepts, Methodologies, Tools, and Applications: Information Science Reference.

Gurevych, V. (2007). Os Commerce Webmaster's Guide to Selling Online: Increase Your Sales and Profits with Experts Tips on SEO, Marketing, Design, and Selling Strategies Etc. Birmingham: Packt Pub.

Hsieh, H.-C. (2006). "A research on the relations among organizational change recognition, organizational commitment and work Performance - take Hsingchung paper company as an example", Taiwan: Master's degree thesis, Graduate Studies of Management, FoGuang University.

Huang, C. L. (2014). The Effects of Knowledge Management on Organizational Performance of Taiwan Listed Communication Network Companies: Using Cloud Technology Investment as the Moderator. Journal of Global Business Management, 10(2), 117.

Jennex, M. E., Amoroso, D., \& Adelakun, O. (2004). E-Commerce Infrastructure Success Factors for Small Companies in Developing Economies. Electronic Commerce Research, 4(1), 263-286.

Kent, A., \& Williams, J. G. (1993). Encyclopedia of Computer Science and Technology: Volume 28 - Supplement 13: AerosPate Applications of Artificial Intelligence to Tree Structures: Taylor \& Francis.

Kurbel, K. (2013). Enterprise Resource Planning and Supply Chain Management. New York: Springer-Verlag Berlin Heidelberg.

Ling, Y. H., \& Hung, L. (2010). The influence of intellectual capital on organizational performance: The mediation effect of intellectual capital management strategy. Human Resource Management Student Newspaper, 10(1), 1-27.

Mahafzah, A. G., Aljawarneh, N. M., Alomari, K. A. K., Altahat, S., \& Alomari, Z. S. Impact of customer relationship management on food and beverage service quality: The mediating role of employees satisfaction. Humanities \& Social Sciences Reviews, 8(2), 222-230.

Manzoor, A. (2010). E-Commerce: An Introduction. Lambert Academic Publishing.

Mohapatra, S. (2013). E-Commerce Strategy. US: Springer.

Müller, D. (2012). Design Characteristics of Virtual Learning Environments: A Theoretical Integration and Empirical Test of Technology Acceptance and IS Success Research, Germany: Springer Fachmedien Wiesbaden.

Olson, J. E. (2003). Data Quality: The Accuracy Dimension. San Francisco, Calif: Morgan Kaufmann.

Sebastian-Coleman, L. (2012). Measuring Data Quality for Ongoing Improvement: A Data Quality Assessment Framework: Elsevier Science.

Sekaran, U., \&Bougie ,R (2015). Research Methods for Business: A Skill-Building Approach. 6th Edition.

Spotts, H. E., \& Meadow, H. L. (2014). Developments in Marketing Science: Proceedings of the Academy of Marketing Science.

Wang, J.-C. (1997). Performance Management. Taipei: Shi-tai Management Consultant.

Xu, J., Fry, J. A., Lev, B., \&Hajiyev, A. (2013). Proceedings of the Seventh International Conference on Management Science and Engineering Management: Focused on Electrical and Information Technology Volume I: Springer.



(C) 2021 by the authors; licensee Growing Science, Canada. This is an open access article distributed under the terms and conditions of the Creative Commons Attribution (CC-BY) license (http://creativecommons.org/licenses/by/4.0/). 